Journal of Applied Pharmaceutical Science Vol. 2 (10), pp. 016-020, October, 2012

Available online at http://www.japsonline.com

DOI: $10.7324 / \mathrm{JAPS} .2012 .21003$

ISSN 2231-3354 (cc) BY-NC-SA

\title{
HPLC evaluation on 3-n-butylphthalide distribution
}

\author{
Qi Wang ${ }^{1,2, \dagger}$, Shuoyang Li $^{3, \dagger}$, Peifeng Liu ${ }^{2}$, Ming Shen ${ }^{2}$, Tao Gong ${ }^{1}$, Yourong Duan ${ }^{2, *}$, Zhang Zhi-Rong ${ }^{1, *}$ \\ ${ }^{1}$ Key Laboratory of Drug Targeting and Novel Drug Delivery Systems, Ministry of Education, West China School of Pharmacy, Sichuan University, \\ Chengdu, Sichuan, 610041, China. \\ ${ }^{2}$ Shanghai Cancer Institute, Renji Hospital, Shanghai Jiao Tong University School of Medicine, Shanghai 200032, China. \\ ${ }^{3}$ Northfield Mount Hermon, Massachuseets 01354, USA.
}

\section{ARTICLE INFO}

Article history:

Received on: 16/09/2012

Revised on: 28/09/2012

Accepted on: 08/10/2012

Available online: $28 / 10 / 2012$

Key words:

HPLC; 3-n-Butylphthalide;

Pharmacokinetic investigation;

Distribution

\begin{abstract}
A rapid, sensitive and specific reversed-phase high-performance liquid chromatographic method was developed for the determination of 3-n-butylphthalide, a drug currently being developed for treatment of stroke, in mice tissue. Ultraviolet detection were monitored at $228 \mathrm{~nm}$ for quantification of 3-nbutylphthalide. Ibuprofen was used as internal standard. The peak area ratio vs concentration in tissue was linear over the range of $25.625-1025.000 \mathrm{ng} / \mathrm{mL}$ and the limit of quantification was $25.625 \mathrm{ng} / \mathrm{mL}$. The method was successfully applied to pharmacokinetic investigation in mice. The mean distribution half-life was $5.471 \pm 4.736 \mathrm{~min}$ and elimination half-life was $58.459 \pm 34.370 \mathrm{~min}$. Finally, a preclinical biodistribution research of 3-n-butylphthalide in mice following intravenous administration had been studied. Brain targeting of 3-n-butylphthalide was strong and metabolism in the liver and blood was rapid.
\end{abstract}

\section{INTRODUCTION}

3-n-Butylphthalide (Fig. 1) was a volatile drug isolated from several plants including Apium graveolens, Ligusticum sinensis and Ligusticum wallichii (Liu and Zhang 2011; Cui et al. 2011; $\mathrm{Xu}$ and Zhao 2011). It has two chiral enantiomers of not equivalent activities (Zhang et al. 2009; Ma and Qu 2007). A series of studies indicated that 3-n-Butylphthalide attenuated cerebral ischemic damage in experimental animals with no marked toxicity. Moreover, 3-n-Butylphthalide was found to attenuate cerebral ischemic damage mainly due to their ability to increase regional cerebral blood flow (rCBF) in the ischemic zone and their inhibitory effects on the release of glutamate and 5hydroxytryptamine (Li et al. 2009; Ma et al. 2009).

$\dagger$ These authors contributed equally to this work.

*Corresponding authors:

Y.R. Duan, Shanghai Cancer Institute, Renji Hospital, Shanghai Jiao Tong University School of Medicine, Shanghai 200032, China.

Email:yrduan@shsci.org

Z.R. Zhang, Key Laboratory of Drug Targeting and Novel Drug Delivery Systems, Ministry of Education, West China School of Pharmacy, Sichuan University, Chengdu, Sichuan, 610041, China.
Therefore, 3-n-Butylphthalide expects to be a promising new drug for the treatment of ischemic cerebral diseases such as stroke. Since 3-n-Butylphthalide is a drug for the treatment of brain diseases, it is very necessary for us to understand the biodistribution especially in the brain. Because it could help us to understand its site of action and the mechanism, but also help to find the target organs, to determine the target, find a new targeting mechanism and provide the basis for the safety data.

However, to date, several reports have explored the 3-nbutylphthalide concentrate in rat plasma and got the pharmacokinetic profile. However, these methods both need special instrument and no one had determined its bio-distribution. Till now, no research on the distribution of 3-n-butylphthalide in the body had been reported. It's no doubt that, the lack of data had limited the application of 3-n-butylphthalide. Combined the methods used for pharmacokinetic study by former scientists, we attempted to develop a novel, rapid, selective and highly sensitive method to determine 3-n-butylphthalide in mice tissues using HPLC after intravenous administration. The result would provide us with new data on its action mechanism and safety evaluation. 


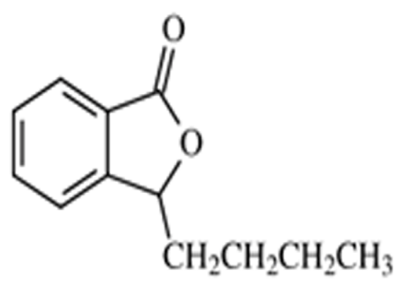

Fig. 1 The structure of 3-n-butylphthalide.

\section{MATERIALS AND METHODS}

\section{Material}

3-n-Butylphthalide was provided by National Institute for Control of Pharmaceutical and Biological Products (Beijing, PR China). The internal standard, Brufen, was purchased from Xinhua Pharmaceutical Co. (Shangdong, China). Acetonitrile and methanol of HPLC-grade were purchased from Shanghai ANPEL Scientific Instrument Co. Ltd (Shanghai, China). All other used reagents were of analytical grade.

\section{Instrument and Operation Conditions}

Analyses were acquired on an Agilent 1200 series (Agilent Corp., Milford, MA, USA) with column oven allowing accurate temperature control of the analytical column. A Kromasil ODS-1 column $(150 \mathrm{~mm} \times 4.6 \mathrm{~mm}, 5 \mu \mathrm{m})$ was used. The mobile phase was a mixture of $0.2 \mathrm{M}$ Sodium Dihydrogen Phosphate (adjusted to $\mathrm{pH} 4.5$ with phosphoric acid) and acetonitrile (50:50, $\mathrm{v} / \mathrm{v}$ ) with the flow rate set at $1.0 \mathrm{~mL} / \mathrm{min}$. The column temperature was maintained at $30{ }^{\circ} \mathrm{C}$. The eluents were monitored at $228 \mathrm{~nm}$ $($ AUFS $=1$ ) (Niu et al. 2008; Zhao et al. 2003a;).

\section{Preparation of Samples}

A 40uL aliquot of the I.S. solution (Brufen, $11 \mu \mathrm{g} / \mathrm{mL}$ ) was added to $200 \mathrm{uL}$ plasma samples (tissue bomogenate liquid) (Zhao et al. 2003a). The samples were deproteinized with $100 \mathrm{uL}$ perchloric acid $\left(6 \% \mathrm{HClO}_{4}\right)$ and $200 \mathrm{uL}$ diethyl ether was added. Followed by vortex for $5 \mathrm{~min}$, the precipitate was removed by centrifugation at $6,000 \times \mathrm{g}$ for $10 \mathrm{~min}$. The supernatant was transferred into a clean glass tube and evaporated to dryness in a water bath at $40{ }^{\circ} \mathrm{C}$ under a flow of nitrogen. The residue was dissolved in $100 \mu \mathrm{L}$ mobile phase by vortex. After centrifugation, $40 \mu \mathrm{L}$ supernatant was injected into the column.

\section{Pharmacokinetic and Biodistribution of 3-n-butylphthalide in mice}

The developed method was used to determine the concentrations of 3-n-butylphthalide in body distribution investigations in 18 healthy Kunming male mice (Laboratory Animal Center of Fudan University, Shanghai, China) weighing 20 $\pm 2 \mathrm{~g}$. The injection was prepared with $0.9 \% \mathrm{NaCl}$ : propylene glycol $(3: 2)$ to give a solution with a concentration of $0.1 \mathrm{mg} / \mathrm{mL}$.
The injection was administrated to mice via the tail vein at a dose of $1 \mathrm{mg} / \mathrm{kg}$. For each preparation, 5, 15, 30, 60, 120 and $240 \mathrm{~min}$ were chosen as sampling points and three mice were killed at each sampling point. The animals were dissected after 0.3 $\mathrm{mL}$ blood samples were collected into heparinized tubes. Then each tested organ (heart, liver, spleen, lung, kidney and brain) was collected. The blood samples were centrifuged immediately at $3500 \mathrm{rpm}$ for $10 \mathrm{~min}$ to obtain plasma. Every tissue sample was accurately weighed, homogenized, and extracted with $0.9 \% \mathrm{NaCl}$ solution to gain a concentration of $500 \mathrm{mg} / \mathrm{mL}$ (Wang et al. 2008; Zhao et al. 2004).

The samples were labeled and kept frozen at $-20{ }^{\circ} \mathrm{C}$ until analysis.

\section{Data Analysis}

Pharmacokinetic parameters were calculated from plasma concentration - time data using a single-dose, twocompartment intravenous model, a practical pharmacokinetic program (the Chinese Society of Mathematical Pharmacology).

\section{RESULTS AND DISCUSSION}

\section{Chromatography}

This chromatographic method was proven fast separations and excellent stability while maintaining satisfactory chromatographic resolution. 3-n-Butylphthalide and the internal standard (Brufen) were well separated under the experimental conditions as described above, with retention times of 6.4 and 6.9 min respectively (Fig. 2).

Because a poor resolution was observed at $\mathrm{pH}$ lower than 4.0 and unsatisfactory peak widths were observed with buffer at $\mathrm{pH}$ higher than 6.0, the final separation of samples was performed at $\mathrm{pH} 4.5$ (Zhao et al. 2003a). Fig. 2 shows that there is no interference from endogenous substances observed at the retention time of the analytes.

Blank plasma samples (tissue homogenate liquid) spiked with seven different concentrations of 3-n-butylphthalide was processed as described in the Experimental section. All chromatograms obtained were estimated by peak area measurement. The calibration curves obtained with peak-area ratio (y) of 3-n-butylphthalide to internal standard versus drug concentration $(\mathrm{x})$ were found to be linear when evaluated by linear regression analysis in the concentration range of 25.625-1025.000 $\mathrm{ng} / \mathrm{mL}$. Typical equations for the calibration curve were list in table 1 .

The precision and accuracy of the assay were estimated by performing the quality control (QC) samples with low, middle and high concentrations. The concentrations of QC samples were calculated from the calibration curve performed on the same day. The results are shown in table 1 . The extraction recovery of 3-nbutylphthalide are shown in table 2 . The mean recovery of the I.S. $(11 \mu \mathrm{g} / \mathrm{mL})$ was $80.16 \%(\mathrm{n}=6)$. 

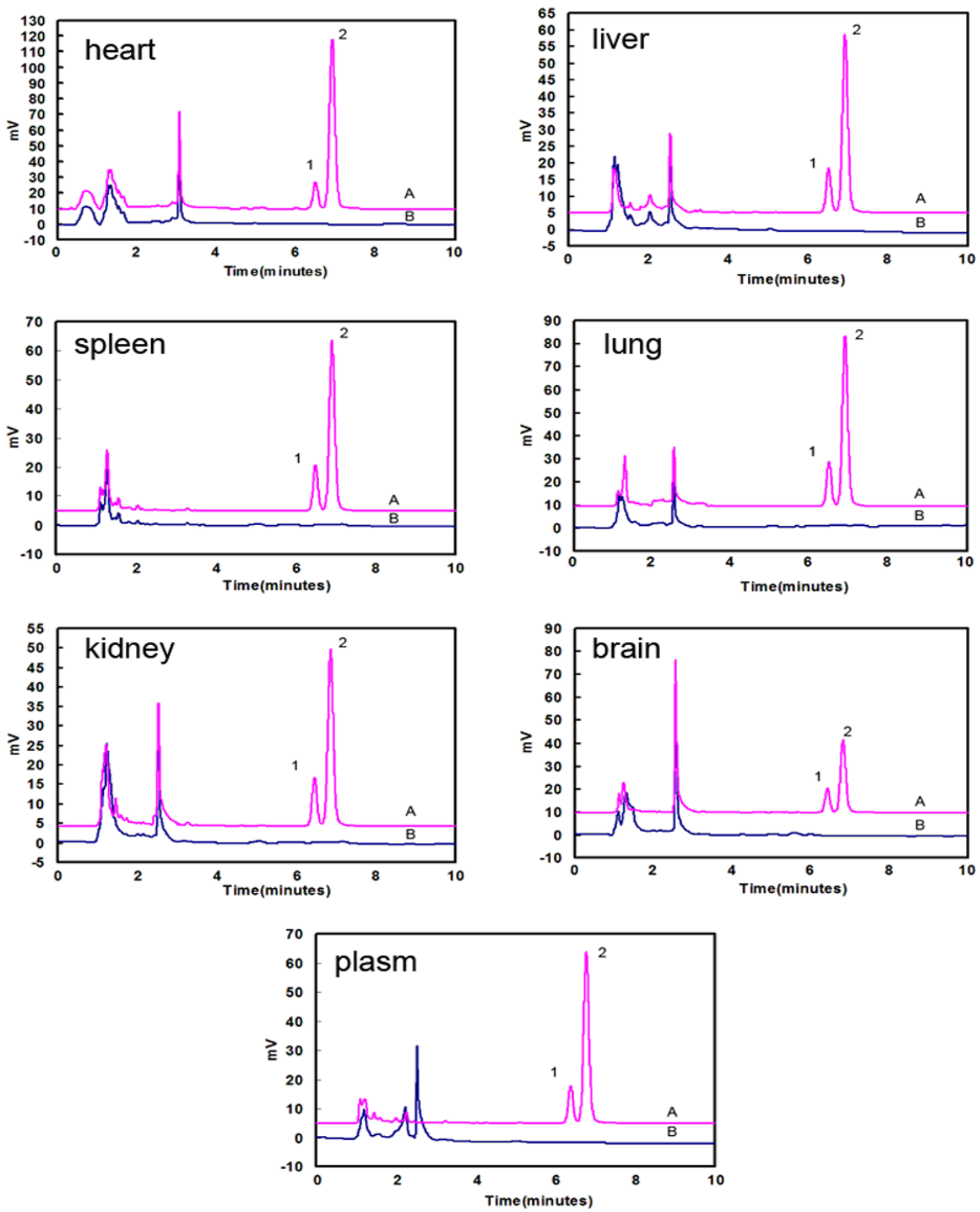

Fig. 2: Chromatograms of 3-n-butylphthalide and ibuprofen in plasma by HPLC. (A) tissue sample; (B) drug-free tissue sample; (1) 3-n-butylphthalide; (2) Brufen 


\section{Pharmacokinetic Study}

Fig. 3 shows the mean plasma concentration - time profiles of 3-n-butylphthalide. Plasma levels of 3-butylphthalide were detectable only up to $240 \mathrm{~min}$. The plasma concentrationtime data fit to a two-compartment intravenous model with a weight of 1 (Fig. 3). The pharmacokinetic parameters are summarized in Table 3. The $\mathrm{AUC}_{0-\mathrm{t}}$ values were 20.

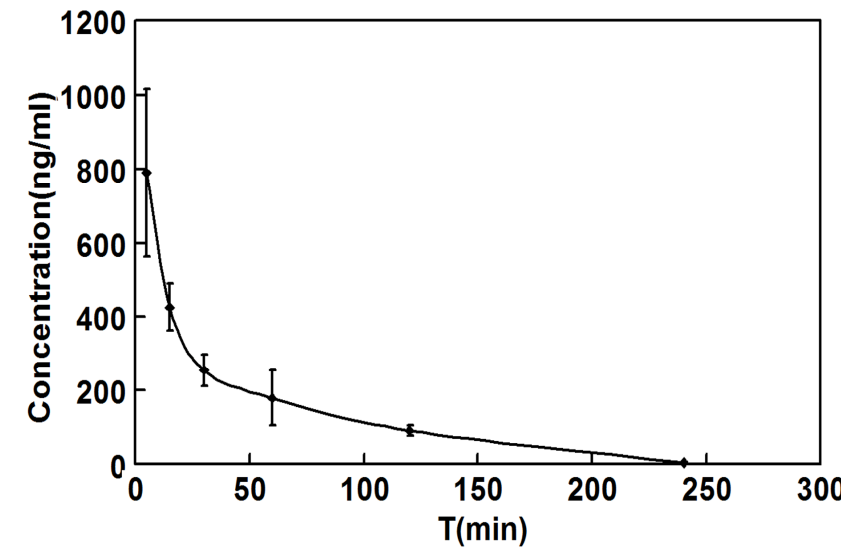

Fig. 3: Mean (SD) plasma concentration-time curves of 3-nbutylphthalide in rabbits $(\mathrm{n}=6)$ after a single $1 \mathrm{mg} / \mathrm{kg}$ intravenous dose of 3-n-butylphthalide and the fitted curves using a single dose, twocompartment intravenous model.

\section{Distribution of 3-n-butylphthalide}

This validated analytical method has been successfully applied to determine the tissue concentrations of 3-nbutylphthalide to support biodistribution studies in rats following intravenous administration. Fig. 4 shows the biodistribution profiles of 3-n-butylphthalide in tested tissues.

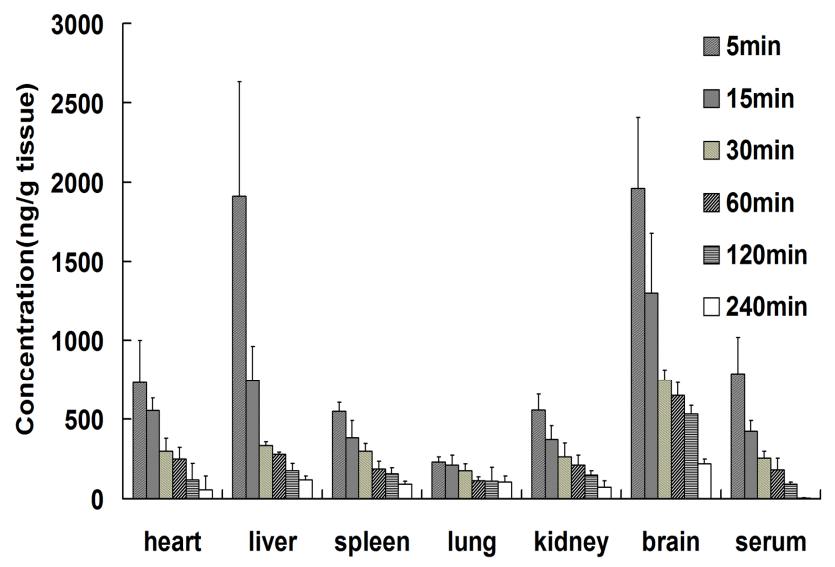

Fig. 4 Drug concentration in various tissues (heart, liver, spleen, lung, kidney, brain, and serum) after i.v. administration of 3-n-butylphthalide at a dose of $0.1 \mathrm{mg} / \mathrm{kg}$. The values are given as mean \pm SD with $\mathrm{n}$ exceeding 3 .

From Fig. 4, we can see that 3-n-butylphthalide mainly distributed in liver and brain tissues. And the concentration in heart and plasma were relatively higher than those in lung and kidney.
The concentrations in all organs reached the maximum values at $5 \mathrm{~min}$ and then quickly decreased. The elimination rate of 3 -n-butylphthalide in the liver and blood was fastest. The content of 3-n-butylphthalide at $15 \mathrm{~min}$ has reduced to half of the content at $5 \mathrm{~min}$. The rapid metabolism of the liver to $3-n$-butylphthalide reduced the drug toxicity. 3-n-butylphthalide quickly distributed into the brain tissue after injection. The drug concentration in brain tissue reached the same concentration as in the liver tissue after 5min, which showed a strong brain targeting ability. However, elimination rate of the 3-n-butylphthalide in the brain tissue was relatively slow. 3-n-butylphthalide content reduce by one third after 15 min while kept strong 30 min later in the brain. We know that the 3-n-butylphthalide is a drug for the treatment of brain diseases, the slower metabolic rate in the brain has extended its duration of action, enhanced its effect.

\section{CONCLUSION}

This paper describes a new method for the determination of 3-n-butylphthalide in mice tissues using HPLC in combination with ultraviolet detection. The method is simple, rapid, and did not require a complex and expensive equipment.

The method was successfully applied to pharmacokinetic investigation in mice after intravenous administration of 3-nbutylphthalide at doses of $1 \mathrm{mg} / \mathrm{kg}$. 3-n-Butylphthalide is rapidly eliminated from the plasma. Mean distrubition and elimination half-life $\left(\mathrm{T}_{1 / 2 \alpha}\right.$, and $\left.\mathrm{T}_{1 / 2 \beta}\right)$, total plasma clearance $(\mathrm{Cl})$, and apparent volume of distribution $(\mathrm{Vc})$ values were listed.

The method has also been successfully applied to a biodistribution study of 3-n-butylphthalide in mice. As indicated by a large Vc value and the distribution profile, 3-n-Butylphthalide is rapidly distributed into the extra-vascular tissues. Brain targeting of 3-n-butylphthalide was strong and metabolism in the liver and blood was rapid which has reduced its toxic side effects. Elimination rate in brain tissue was slow, which has extended its duration of action, enhanced its effect.

In summary, this paper provides not only a simple, sensitive and specific HPLC method for the determination of 3-nbutylphthalide in rat tissues, but also information about the pharmacokinetic and biodistribution of 3-n-butylphthalide, which would be of great value in the development of this new drug.

\section{ACKNOWLEDGEMENTS}

We gratefully acknowledge the financial support from the National Natural Science Foundation of China (No.81101738) and Biological pharmaceutical and agricultural fields from Science and Technology Commission of Shanghai Municipality (No. 114119a3300).

\section{COMPETING INTERESTS STATEMENT}

The authors declare that they have no conflict of interest. 


\section{REFERENCES}

Cui JH., Bai IY., Tang W., Wang Y. Effect of Butylphthalide capsules on serum neuron- specific enolase levels of acute massive cerebral infarction. China Medicine and Pharmacy 2011;2:21-22.

Liu XH., Zhang YX. Effect of butylphthalide on the expression of caspase-3 and SOD in hippocampus tissue of rats with cerebral ischemia-reperfusion. China Pharmacy. 2011;22:410-412.

Li L., Zhang B., Tao YQ., Wang Y., Wei H., Zhao J., Huang RX., Pei Z. DL-3-n-butylphthalide protects endothelial cells against oxidative/nitrosative stress, mitochondrial damage and subsequent cell death after oxygen glucose deprivation in vitro. Brain Research 2009;1290:91-101.

Ma YK., Qu GM. The effects of Butyl-phthalide on impairment of memory model mice. Qilu Pharmaceutical Affairs 2007;26:562-564.

Ma SP., Xu SF., Liu B., Li J., Feng N., Wang L., Wang XL. Long-term treatment of 1-3-n-butylphthalide attenuated neurodegenerative changes in aged rats. Naunyn-Schmiedebergs Archives of Pharmacology 2009;379:565-574.

Niu ZQ., Chen FJ., Sun J., Liu XH., Wang YJ., Chen DW., He ZG. High-performance liquid chromatography for the determination of 3 - n-butylphthalide in rat plasma by tandem quadrupole mass spectrometry: Application to a pharmacokinetic study. Journal of Chromatography B 2008; 870:135-139.

Wang SC., Shi YF., Chen QH., He LC. A GC-SIM-MS method for the determination of butylidenephthalide in rat plasma and tissue: application to the pharmacokinetic and tissue distribution study. Analytical Letters 2008; 41:1975-1987.

Xu B., Zhao ZG. Butylphthalide injection, an innovative drug originated in China for the treatment of ischemic stroke. Chinese Journal of New Drugs 2011;20: 947-950.

Zhang GY., Cheng ZF., Liu JF., Xu L., Qin J. Anti-aging action of butylphthalide on galactose model mice. Journal of Chinese Hospital Pharmaceutical 2009; 29:1737-1739.

Zhao CS., He ZG., Cui SM., Zhang RH. Determination of 3-nbutylphthalide in rabbit plasma by HPLC with fluorescence detection and its application in pharmacokinetic study. Biomedical Chromatography 2003a; $17: 391-395$.

Zhao CS., Cui SM., Liu XH., Liu YL., He ZG., Zhang RH. Determination of the content and the related substances of 3-nbutylphthalide in liposomes by RP-HPLC. Journal of Shenyang Pharmaceutical University 2004; 21:24-27.

\section{How to cite this article:}

Qi Wang, Shuoyang Li, Peifeng Liu, Ming Shen, Tao Gong, Yourong Duan, Zhang Zhi-Rong. HPLC evaluation on 3-n-butylphthalide distribution. J App Pharm Sci. 2012; 2 (10): 016-020. 